\title{
A study on the effective management of pain in major traumas
}

\author{
Kevin Dodd", Anthony Hudson, Heather Jarman \\ From London Trauma Conference 2013 \\ London, UK. 10-13 December 2013
}

\section{Background}

Pain associated with major trauma often remains uncontrolled by medical professionals in Emergency Departments (ED). This study was established in an attempt to gauge the efficacy of pain control in major traumas by determining the time taken to get patients pain under control.

The study also aimed to look at the types of analgesia being used and the efficacy of pre-hospital analgesia.

\section{Methods}

Only patients that triggered the activation of the Major Trauma team were included in the study.

Over a 3 week period, patients meeting the inclusion criteria were questioned on arrival and initial pain score was taken. Information about the presenting complaint and en-route medication was also recorded. Patients were followed up every 10 minutes with their pain score, analgesia, procedures and treatments recorded. The patients were followed up until such a time as they reported two consecutive pain scores of 2 or until they reported that their pain was sufficiently controlled.

\section{Results}

A total of 16 people were included in the study, 8 males and 8 females.

On average it took 80 minutes to achieve pain control with females reporting a higher time of 87.5 minutes compared to 74.5 minutes in males. The average time for pain control was 116 minutes for patients receiving IV morphine only, 61 minutes for patients receiving IV paracetamol only, 135 minutes for those receiving both IV paracetamol and IV morphine and 85 minutes for those receiving oral analgesia only.

The average pain score on arrival to the ED was 6.06.

\section{Conclusions}

This study highlights the need for faster and better intervention for pain control in Major Traumas.

Several methods could be implemented to achieve this:

-Implementing more regular pain scoring.

- The possible use of alternative pain medication or nerve blocks.

- Recommend a review of pain management in prehospital services.

Published: 7 July 2014

doi:10.1186/1757-7241-22-S1-P14

Cite this article as: Dodd et al:: A study on the effective management of pain in major traumas. Scandinavian Journal of Trauma, Resuscitation and Emergency Medicine 2014 22(Suppl 1):P14.
Submit your next manuscript to BioMed Central and take full advantage of:

- Convenient online submission

- Thorough peer review

- No space constraints or color figure charges

- Immediate publication on acceptance

- Inclusion in PubMed, CAS, Scopus and Google Scholar

- Research which is freely available for redistribution
() Biomed Central 